\title{
LISICON-Based Amorphous Oxide for Bulk-Type All-Solid-State Lithium-Ion Battery
}

Toyoki Okumura, ${ }^{*} \dagger$ Sou Taminato, ${ }^{\dagger} \S$ Yoshinobu Miyazaki, ${ }^{\ddagger}$ Michinori Kitamura, ${ }^{\ddagger}$ Tomohiro Saito, ${ }^{\star}$ Tomonari Takeuchi, ${ }^{\dagger}$ and Hironori Kobayashi ${ }^{\dagger}$

$\uparrow$ Research Institute of Electrochemical Energy, National Institute of Advanced Industrial Science and Technology (AIST), 1-8-31 Midorigaoka, Ikeda, Osaka 563-8577, Japan

+ Tsukuba Laboratory, Technical Solution Headquarters, Sumika Chemical Analysis Service (SCAS), Ltd., 6 Kitahara, Tsukuba, Ibaraki 300-3266, Japan

$\S$ Department of Chemistry, Mie University, 1577 Kurimamachiya-cho, Tsu, Mie 514-8507, Japan

KEYWORDS: all-solid-state Li-ion battery, LISICON, solid-state electrolyte, spark-plasma sintering, low-temperature densification

*E-mail: toyoki-okumura@aist.go.jp 


\section{Phenomena under ball-milling}

The solo-LGPO powder $(x=0)$ likely adhered to the bottom corners of the $\mathrm{ZrO}_{2}$ pot after treatment. Therefore, the long-period arrangement of the crystalline LGPO was difficult to break, even though the adhered powder was raked out several times during the treatment. On the other hand, the $\mathrm{LGPO}-\mathrm{Li}_{3} \mathrm{BO}_{3}$ blended powder was more likely to adhere to the surfaces of the $\mathrm{ZrO}_{2}$ balls than to the walls of the $\mathrm{ZrO}_{2}$ pot, resulting in a thicker covering of the balls with increased $\mathrm{Li}_{3} \mathrm{BO}_{3}$ additive ratio. Thus, the amorphization of $\mathrm{LGPO}-\mathrm{Li}_{3} \mathrm{BO}_{3}$ was promoted by introducing an effective impact via $\mathrm{ZrO}_{2}$ balls to the covered powder. Actually, slight peaks remained in the treated LGPO with a low $\mathrm{Li}_{3} \mathrm{BO}_{3}$ additive amount $(x=1 / 7)$ associated with the increase in bottom-corner adhesion. On the other hand, crystalline peaks were also confirmed from solo- $\mathrm{Li}_{3} \mathrm{BO}_{3}(x=1)$ in spite of the effective treatment achieved by the $\mathrm{Li}_{3} \mathrm{BO}_{3}$-covered balls [Figure 1(h)]. These peaks indicate that the compositional combination of $\mathrm{LGPO}$ and $\mathrm{Li}_{3} \mathrm{BO}_{3}$, in addition to the ball-adhering effect by $\mathrm{Li}_{3} \mathrm{BO}_{3}$ additive, was also important for amorphization. 


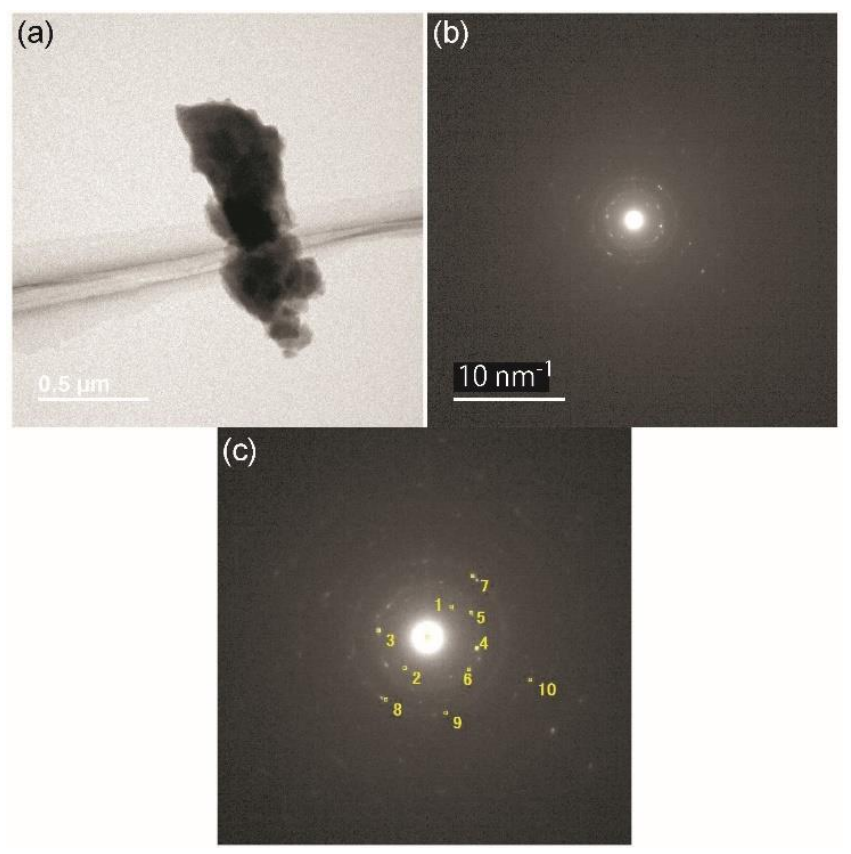

Figure S1. (a) Bright-field TEM image and (b) selected-area electron diffraction of crystalline LGPO electrolyte. (c) Selected diffraction spots for estimating the reflection planes of LGPO.

Table S1. Reflection planes of LGPO corresponding to selected diffraction spots in Figure S1(c).

\begin{tabular}{cccc}
\hline Spot number & $d^{*} / \mathrm{nm}^{-1}$ & Amplitude & $\begin{array}{c}\text { Reflection plane candidate of } \\
\mathrm{Li}_{3.75} \mathrm{Ge}_{0.75} \mathrm{P}_{0.25} \mathrm{O}_{4}\end{array}$ \\
\hline$\# 1$ & 1.88 & 1377 & 200 \\
$\# 2$ & 1.86 & 1311 & 200 \\
$\# 3$ & 2.40 & 2430 & 210 \\
$\# 4$ & 2.50 & 3645 & 210 or 011 \\
$\# 5$ & 2.46 & 1680 & 210 or 011 \\
$\# 6$ & 2.59 & 1380 & 011 or 201 \\
$\# 7$ & 3.71 & 2522 & 220,400, or 311 \\
$\# 8$ & 3.66 & 1299 & 220,400, or 311 \\
$\# 9$ & 3.80 & 740 & 220,400, or 311 \\
$\# 10$ & 5.46 & 1037 & 402 or 222 \\
\hline
\end{tabular}



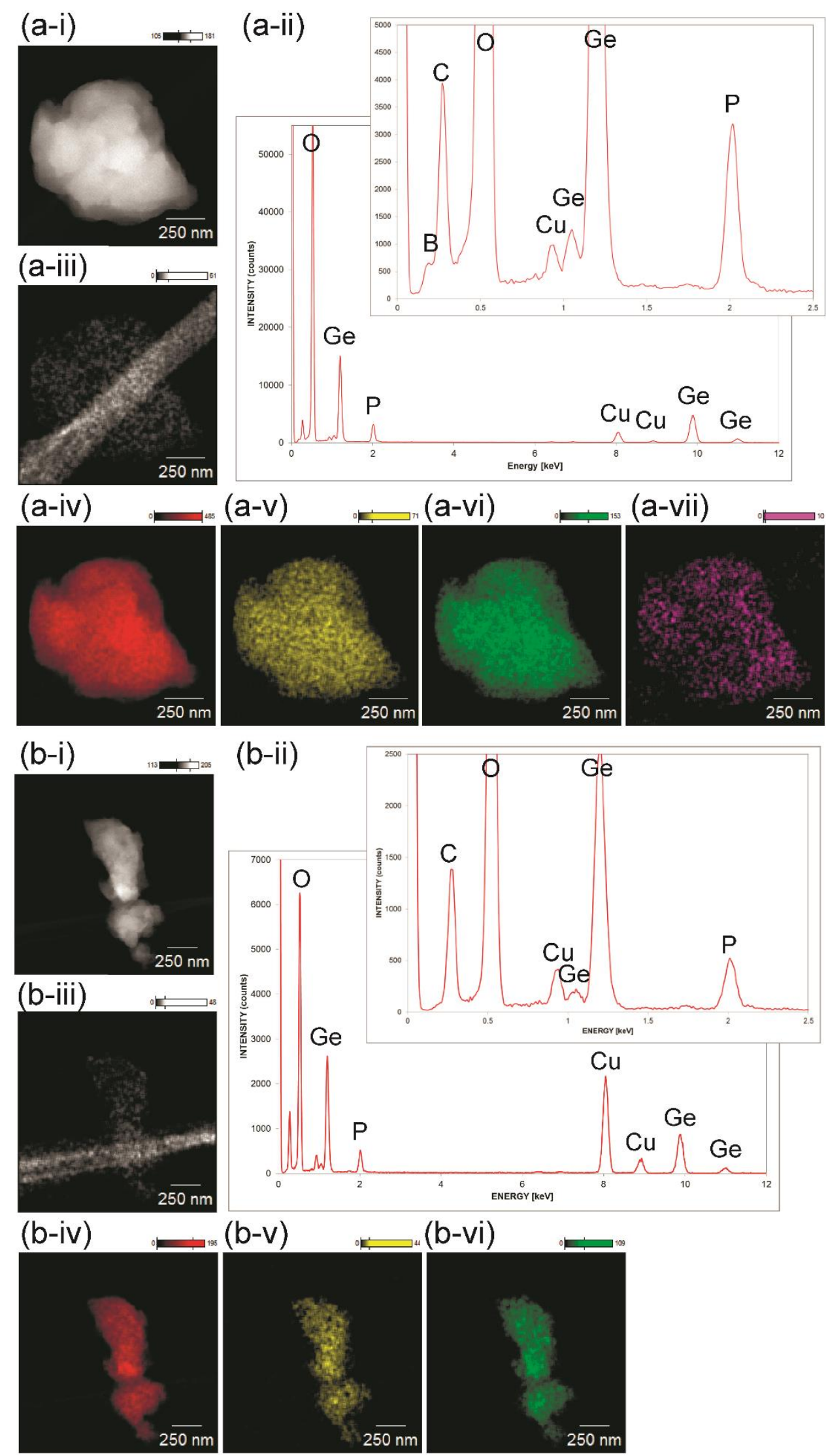

Figure S2. STEM-EDS results of (a) amorphous $0.5 \mathrm{LGPO}-0.5 \mathrm{Li}_{3} \mathrm{BO}_{3}$ and (b) LGPO; (i) STEM image, (ii) EDS spectrum, and STEM-EDS mappings of (iii) C, (iv) O, (v) P, (vi) Ge, and (vii) B. 


\section{Wide amorphization permissibility of LISICON-based oxides}

The amorphization of LISICON-based oxides was attempted with other LISICON-borate additive combinations, whose powder XRD patterns are shown in Figure S3. Amorphous halo patterns were confirmed in all of the LISICON-Li $\mathrm{BO}_{3}$ samples in the present study with crystalline LISICON phases of $\gamma$ - $\mathrm{Li}_{3} \mathrm{PO}_{4}$-type $\mathrm{Li}_{3.5} \mathrm{Ge}_{0.5} \mathrm{~V}_{0.5} \mathrm{O}_{4}, \quad \gamma-\mathrm{Li}_{3} \mathrm{PO}_{4}$-type $\mathrm{Li}_{3.5} \mathrm{Ge}_{0.75} \mathrm{~S}_{0.25} \mathrm{O}_{4}$, and $\mathrm{Li}_{4} \mathrm{SiO}_{4}$-type $\mathrm{Li}_{3.625} \mathrm{Si}_{0.375} \mathrm{Al}_{0.125} \mathrm{P}_{0.5} \mathrm{O}_{4}$ [Figure $\left.\mathrm{S} 3(\mathrm{a}-\mathrm{c})\right] . \quad\left(\mathrm{Li}_{4} \mathrm{SiO}_{4}\right.$-type ionic conductors have sometimes been included in the LISICON family.) Moreover, a similar LISICON-based amorphous phase could also be prepared from other borate additives such as $\mathrm{Li}_{4} \mathrm{~B}_{2} \mathrm{O}_{5}, \mathrm{LiBO}_{2}$, and $\mathrm{B}_{2} \mathrm{O}_{3}$ [Figure $\mathrm{S} 3(\mathrm{~d}-\mathrm{f})$ ] in spite of their structural differences, resulting in different chain-network structures consisting of $\mathrm{BO}_{3}{ }^{3-}$ triangles and $\mathrm{BO}_{4}{ }^{5-}$ tetrahedrons. Therefore, LISICON-based amorphous materials could also be prepared with various borate additives. We also attempted to prepare amorphous electrolytes with other electrolyte candidates (NASICON-type, perovskite-type, and garnet-type oxides) and other Li-salt additives $\left(\mathrm{Li}_{2} \mathrm{CO}_{3}, \mathrm{Li}_{2.2} \mathrm{C}_{0.8} \mathrm{~B}_{0.2} \mathrm{O}_{3}\right.$, and $\left.\mathrm{LiNO}_{3}\right)$, whose powder XRD patterns and conductivities are shown in Figure S4 and Table S2, respectively. In most cases, crystalline phases remained in other electrolyteadditive combinations after the ball-milling treatment, while some advantages were confirmed from carbonate additives. Although a NASICON-type electrolyte was also suitable for preparing the amorphous electrolyte by ball-milling with a borate additive, the conductivity was quite low at $3.2 \times 10^{-}$ ${ }^{8} \mathrm{~S} \mathrm{~cm}^{-1}$. 


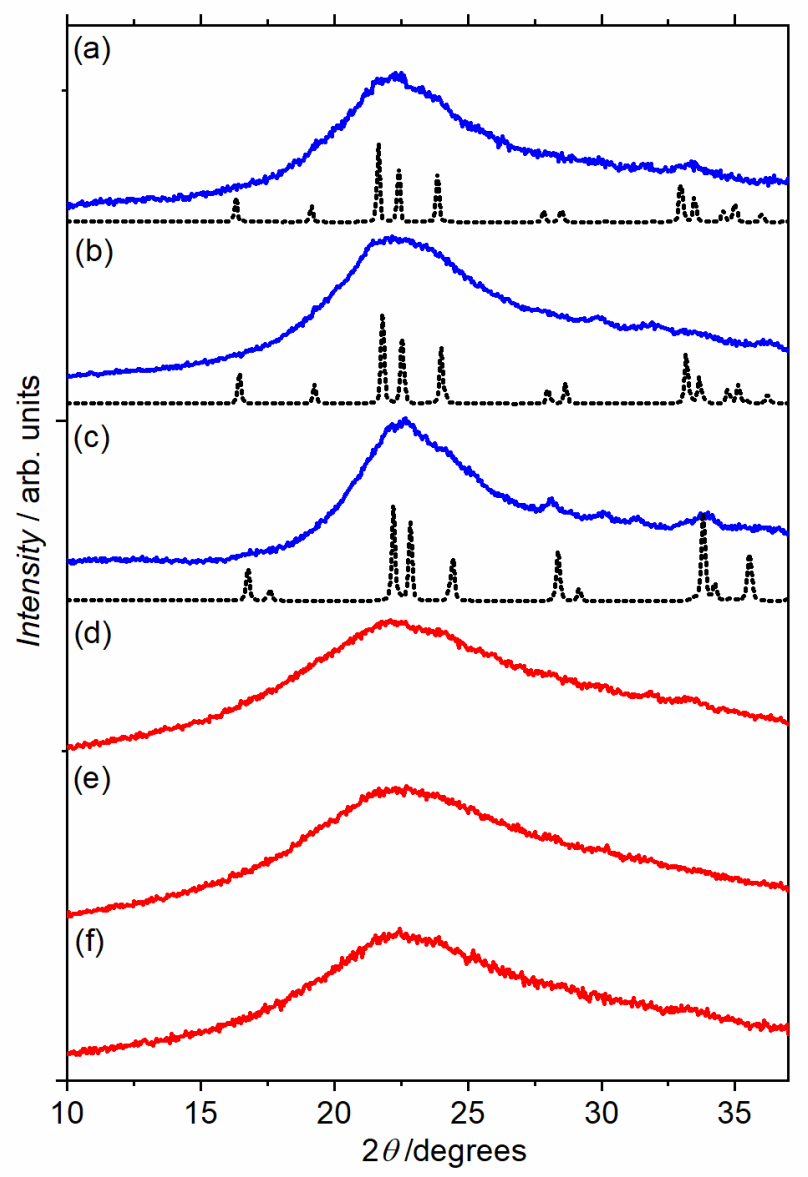

Figure S3. Powder XRD patterns of (a) $0.5 \mathrm{Li}_{3.5} \mathrm{Ge}_{0.5} \mathrm{~V}_{0.5} \mathrm{O}_{4}-0.5 \mathrm{Li}_{3} \mathrm{BO}_{3}$, (b) $0.5 \mathrm{Li}_{3.5} \mathrm{Ge}_{0.75} \mathrm{~S}_{0.25} \mathrm{O}_{4}$ $0.5 \mathrm{Li}_{3} \mathrm{BO}_{3}$, (c) $0.5 \mathrm{Li}_{3.625} \mathrm{Si}_{0.375} \mathrm{Al}_{0.125} \mathrm{P}_{0.5} \mathrm{O}_{4}-0.5 \mathrm{Li}_{3} \mathrm{BO}_{3}$, (d) $0.5 \mathrm{Li}_{3.5} \mathrm{Ge}_{0.5} \mathrm{P}_{0.5} \mathrm{O}_{4}-0.25 \mathrm{Li}_{4} \mathrm{~B}_{2} \mathrm{O}_{5}$, (e) $0.5 \mathrm{Li}_{3.5} \mathrm{Ge}_{0.5} \mathrm{P}_{0.5} \mathrm{O}_{4}-0.5 \mathrm{LiBO}_{2}$, and (f) $0.5 \mathrm{Li}_{3.5} \mathrm{Ge}_{0.5} \mathrm{P}_{0.5} \mathrm{O}_{4}-0.25 \mathrm{~B}_{2} \mathrm{O}_{3}$ after ball-milling treatment. The patterns of crystalline (a) $\mathrm{Li}_{3.5} \mathrm{Ge}_{0.5} \mathrm{~V}_{0.5} \mathrm{O}_{4}$, (b) $\mathrm{Li}_{3.5} \mathrm{Ge}_{0.75} \mathrm{~S}_{0.25} \mathrm{O}_{4}$, and (c) $\mathrm{Li}_{3.625} \mathrm{Si}_{0.375} \mathrm{Al}_{0.125} \mathrm{P}_{0.5} \mathrm{O}_{4}$ are also shown as dashed lines. 


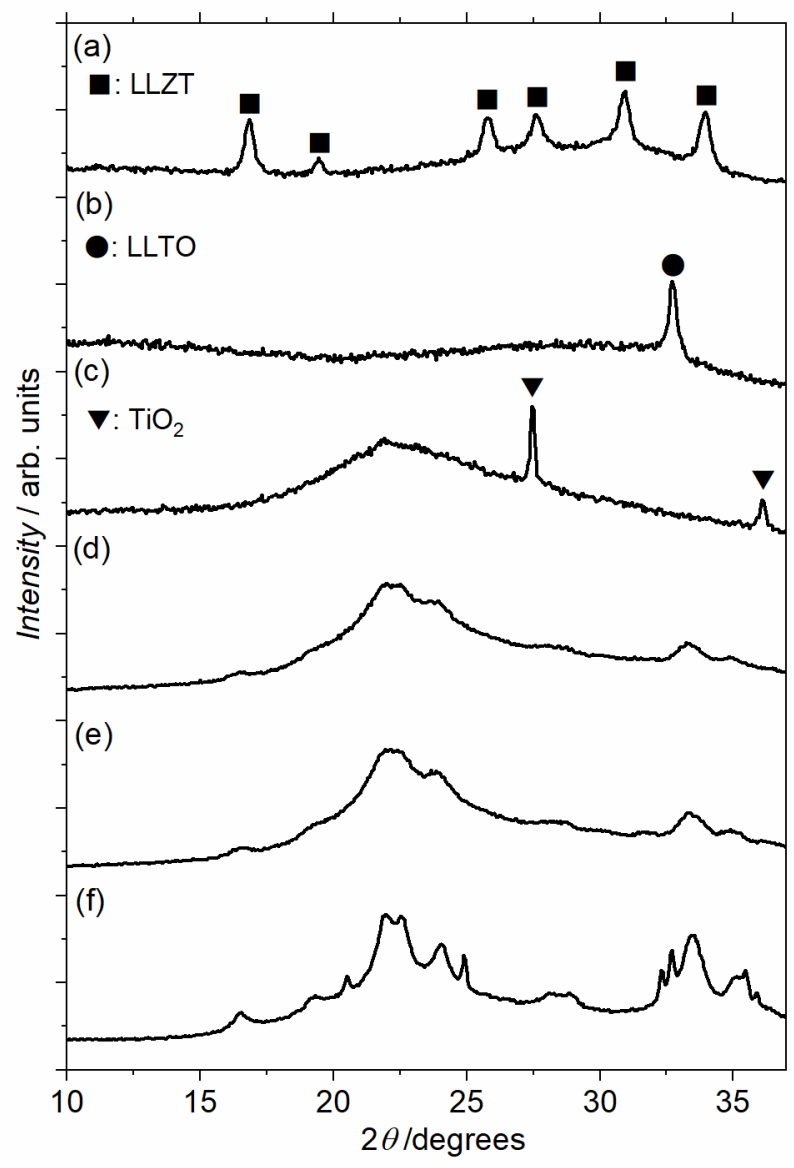

Figure S4. Powder XRD patterns of (a) 0.25 [garnet-type $\mathrm{Li}_{6.5} \mathrm{La}_{3} \mathrm{Zr}_{1.5} \mathrm{Ta}_{0.5} \mathrm{O}_{12}$ (LLZT)]-0.75 $\mathrm{Li}_{3} \mathrm{BO}_{3}$, (b) 0.5 [perovskite-type $\mathrm{Li}_{0.33} \mathrm{La}_{0.56} \mathrm{TiO}_{3}$ (LLTO)]-0.5 $\mathrm{Li}_{3} \mathrm{BO}_{3}$, (c) 0.25 [NASICON-type Al-doped $\left.\mathrm{LiTi}_{2}\left(\mathrm{PO}_{4}\right)_{3}\right]-0.75 \mathrm{Li}_{3} \mathrm{BO}_{3}$, (d) $0.5 \mathrm{LGPO}-0.5 \mathrm{Li}_{2} \mathrm{CO}_{3}$, (e) $0.5 \mathrm{LGPO}-0.5 \mathrm{Li}_{2.2} \mathrm{C}_{0.8} \mathrm{~B}_{0.2} \mathrm{O}_{3}$, and (f) $0.5 \mathrm{LGPO}-0.5 \mathrm{LiNO}_{3}$ after ball-milling treatment.

Table S2. Conductivities at $25^{\circ} \mathrm{C}$ for various Li-ion conductive oxide-additive blended electrolytes by ball-milling treatment.

\begin{tabular}{cccc}
\hline Li-ion conductive oxide & Additive & Blending molar ratio & Conductivity at $25^{\circ} \mathrm{C} / \mathrm{S} \mathrm{cm}^{-1}$ \\
\hline $\mathrm{Li}_{3.75} \mathrm{Ge}_{0.75} \mathrm{P}_{0.25} \mathrm{O}_{4}$ & $\mathrm{Li}_{3} \mathrm{BO}_{3}$ & $1: 1$ & $1.5 \times 10^{-6}$ \\
$\mathrm{Li}_{3.75} \mathrm{Ge}_{0.75} \mathrm{P}_{0.25} \mathrm{O}_{4}$ & - & $1: 0$ & $6.3 \times 10^{-7}$ \\
$\mathrm{Li}_{3.75} \mathrm{Ge}_{0.75} \mathrm{P}_{0.25} \mathrm{O}_{4}$ & $\mathrm{LiBO}_{2}$ & $1: 1$ & $1.0 \times 10^{-7}$ \\
$\mathrm{Li}_{3.75} \mathrm{Ge}_{0.75} \mathrm{P}_{0.25} \mathrm{O}_{4}$ & $\mathrm{~B}_{2} \mathrm{O}_{3}$ & $2: 1$ & $1.4 \times 10^{-8}$ \\
$\mathrm{Li}_{6.6} \mathrm{La}_{3} \mathrm{Zr}_{1.6} \mathrm{Ta}_{0.4} \mathrm{O}_{12}$ & $\mathrm{Li}_{3} \mathrm{BO}_{3}$ & $1: 3$ & unmeasurable \\
$\mathrm{Li}_{0.33} \mathrm{La}_{0.56} \mathrm{TiO}_{3}$ & $\mathrm{Li}_{3} \mathrm{BO}_{3}$ & $1: 1$ & unmeasurable \\
$\mathrm{Al}_{-}$doped $\mathrm{LiTi}_{2}\left(\mathrm{PO}_{4}\right)_{3}$ & $\mathrm{Li}_{3} \mathrm{BO}_{3}$ & $1: 3$ & $3.2 \times 10^{-8}$ \\
$\mathrm{Li}_{3.75} \mathrm{Ge}_{0.75} \mathrm{P}_{0.25} \mathrm{O}_{4}$ & $\mathrm{Li}_{2} \mathrm{CO}_{3}$ & $1: 1$ & $9.5 \times 10^{-7}$ \\
$\mathrm{Li}_{3.75} \mathrm{Ge}_{0.75} \mathrm{P}_{0.25} \mathrm{O}_{4}$ & $\mathrm{Li}_{2.2} \mathrm{C}_{0.8} \mathrm{~B}_{0.2} \mathrm{O}_{3}$ & $1: 1$ & $9.3 \times 10^{-7}$ \\
$\mathrm{Li}_{3.75} \mathrm{Ge}_{0.75} \mathrm{P}_{0.25} \mathrm{O}_{4}$ & $\mathrm{LiNO}_{3}$ & $1: 1$ & $1.8 \times 10^{-7}$ \\
\hline
\end{tabular}




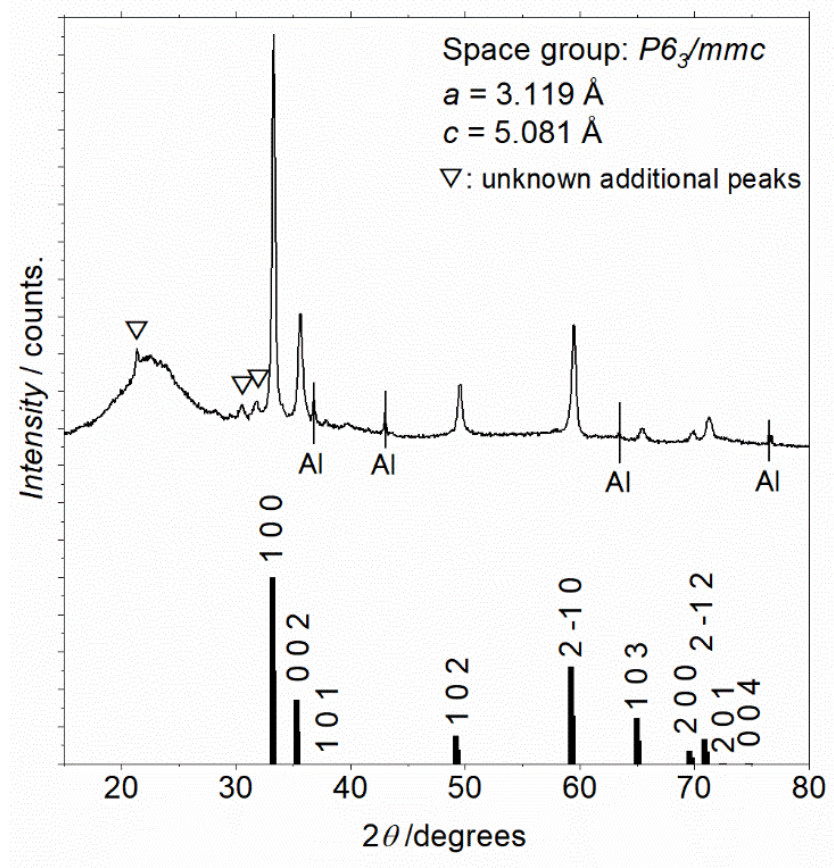

Figure S5. Powder XRD patterns of amorphous $0.5 \mathrm{LGPO}-0.5 \mathrm{Li}_{3} \mathrm{BO}_{3}$ after heat treatment at $400{ }^{\circ} \mathrm{C}$ and simulated pattern of hexagonal structure (space group: $P 6_{3} / \mathrm{mmc}$ ).
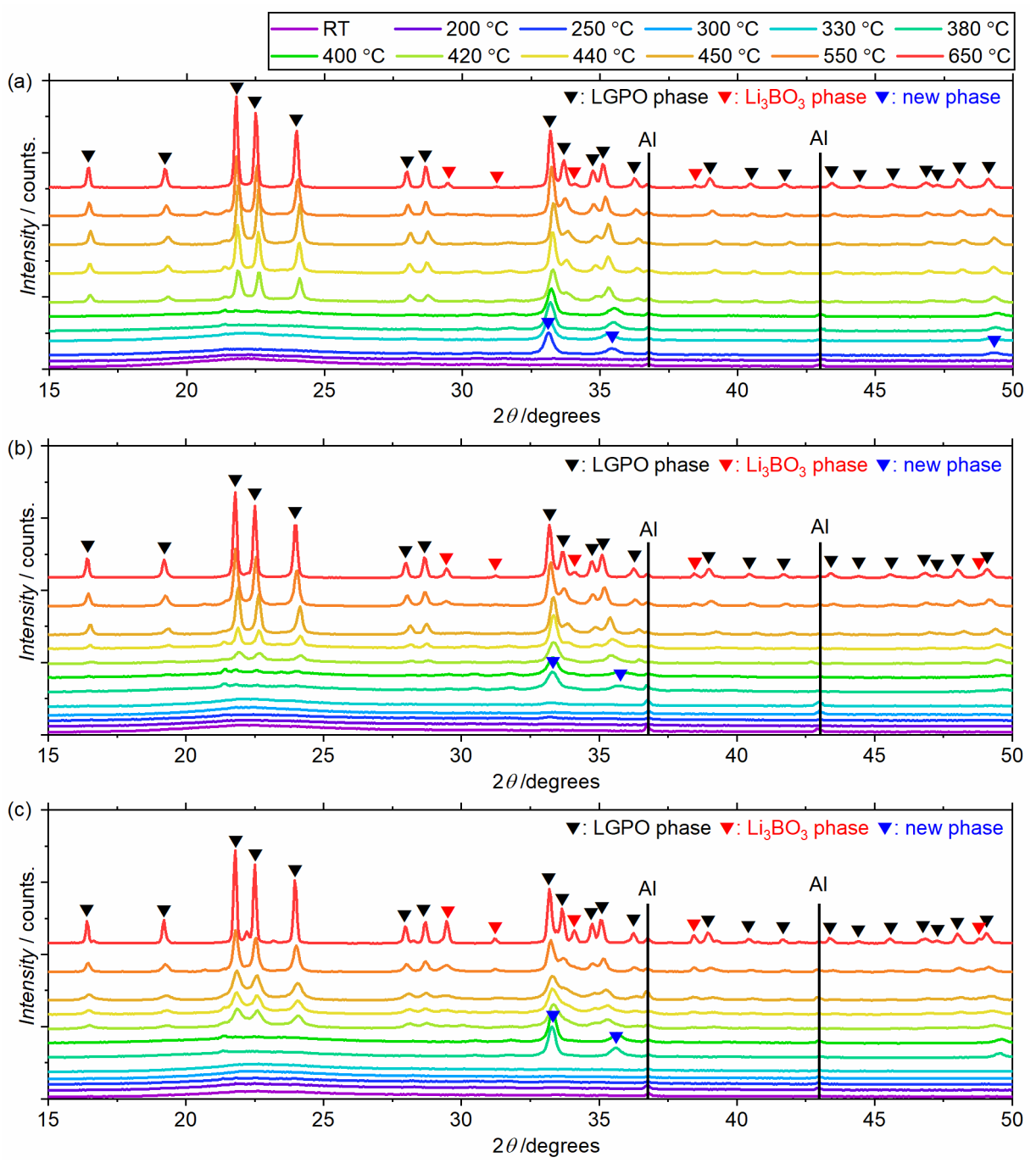

Figure S6. XRD patterns of (a) $0.8 \mathrm{LGPO}-0.2 \mathrm{Li}_{3} \mathrm{BO}_{3}$, (b) $0.67 \mathrm{LGPO}-0.33 \mathrm{Li}_{3} \mathrm{BO}_{3}$, and (c) $0.5 \mathrm{LGPO}-$ $0.5 \mathrm{Li}_{3} \mathrm{BO}_{3}$ amorphous compacts after heat treatment at various temperatures. 


\section{Ionic conductivities and microstructures after heat treatment}

Figure S7 shows Arrhenius plots for the ionic conductivities of the uniaxially pressed (1$x)$ LGPO- $x \mathrm{Li}_{3} \mathrm{BO}_{3}$ amorphous compacts $(x=0.2,0.33,0.5)$ and of pure LGPO sintered by SPS at various operating temperatures. As discussed above, the conductivity of the $700-{ }^{\circ} \mathrm{C}$-heated $(1-$ $x)$ LGPO- $x \mathrm{Li}_{3} \mathrm{BO}_{3}$ compact was close to but slightly less than that of the pure LGPO sintered compact at each temperature since mixing of the low-conductivity $\mathrm{Li}_{3} \mathrm{BO}_{3}$ additive reduces the total conductivity. However, the activation energy for ionic conduction of $(1-x) \mathrm{LGPO}-x \mathrm{Li}_{3} \mathrm{BO}_{3}, E_{a}=0.48$ $\mathrm{eV}$, estimated from the slope of the Arrhenius plots did not change with the $\mathrm{Li}_{3} \mathrm{BO}_{3}$ additive ratio and was similar to that of the pure LGPO sintered compact $\left(E_{a}=0.47 \mathrm{eV}\right)$, as summarized in Table S3. To investigate this observation, the microstructure of the $700-{ }^{\circ} \mathrm{C}$-heated $(1-x) \mathrm{LGPO}-x \mathrm{Li}_{3} \mathrm{BO}_{3}$ compacts was observed. As illustrated in Figure S8(a-c), the LGPO crystalline grains (light-gray) and $\mathrm{Li}_{3} \mathrm{BO}_{3}$ crystalline grains (dark-gray or black) nucleated separately, which agrees with the XRD results [Figure S6(a-c)]. Additionally, the SEM-EDX mappings of Ge in Figure S8(d-f) confirm the distribution of LGPO crystalline grains (green) in the compacts. For samples with less $\mathrm{Li}_{3} \mathrm{BO}_{3}$ additive ( $x=0.2$ or 0.33 ), the compact was mostly formed by connected LGPO crystalline grains, and the $\mathrm{Li}_{3} \mathrm{BO}_{3}$ crystalline grains (or pores) filled in the gaps. The LGPO-connected paths became thin with an increased amount of $\mathrm{Li}_{3} \mathrm{BO}_{3}$ additive $(x=0.5)$ in the compact but were still connected and associated with the formation of an LGPO mesh network. Therefore, the increase in low-conductivity $\mathrm{Li}_{3} \mathrm{BO}_{3}$ additive resulted in a decrease in the pre-exponential factor but did not affect the activation energy $E_{a}$. 


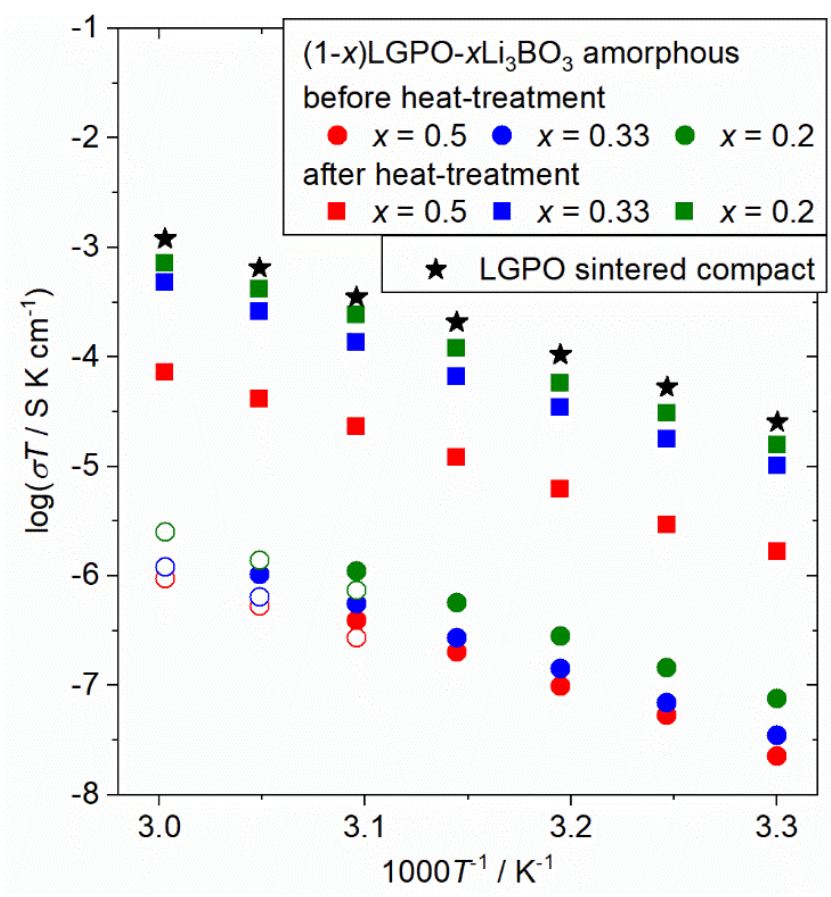

Figure S7. Arrhenius plots of ionic conductivities estimated from Nyquist plots of Au/uniaxially pressed $(1-x) \mathrm{LGPO}-x \mathrm{Li}_{3} \mathrm{BO}_{3}$ amorphous pellet/Au $(x=0.2,0.33,0.5)$ at various operating temperatures before heat treatment (circles) and after $700{ }^{\circ} \mathrm{C}$ heat treatment (squares). Those of $\mathrm{Au} /$ pure LGPO sintered pellet/Au are also shown (stars).

Table S3. Activation energies $E_{a}$ for ionic conduction of LGPO and (1-x)LGPO- $x \mathrm{Li}_{3} \mathrm{BO}_{3}$ estimated from the slope of the Arrhenius plots

\begin{tabular}{cc}
\hline & Activation energy $E_{a} / \mathrm{eV}$ \\
\hline $\mathrm{Li}_{3.75} \mathrm{Ge}_{0.75} \mathrm{P}_{0.25} \mathrm{O}_{4}(\mathrm{LGPO})$ compact sintered by SPS at $800{ }^{\circ} \mathrm{C}$ & 0.47 \\
Amorphous 0.8LGPO-0.2 $\mathrm{Li}_{3} \mathrm{BO}_{3}$ before heat treatment & 0.51 \\
Amorphous 0.67LGPO-0.33 $\mathrm{Li}_{3} \mathrm{BO}_{3}$ before heat treatment & 0.49 \\
Amorphous 0.5LGPO-0.5 $\mathrm{Li}_{3} \mathrm{BO}_{3}$ before heat treatment & 0.50 \\
Amorphous 0.8LGPO-0.2 $\mathrm{Li}_{3} \mathrm{BO}_{3}$ after $700-{ }^{\circ} \mathrm{C}$ heat treatment & 0.48 \\
Amorphous 0.67LGPO-0.33 $\mathrm{Li}_{3} \mathrm{BO}_{3}$ after $700-{ }^{\circ} \mathrm{C}$ heat treatment & 0.48 \\
Amorphous 0.5LGPO-0.5 $\mathrm{Li}_{3} \mathrm{BO}_{3}$ after $700-{ }^{\circ} \mathrm{C}$ heat treatment & 0.48
\end{tabular}



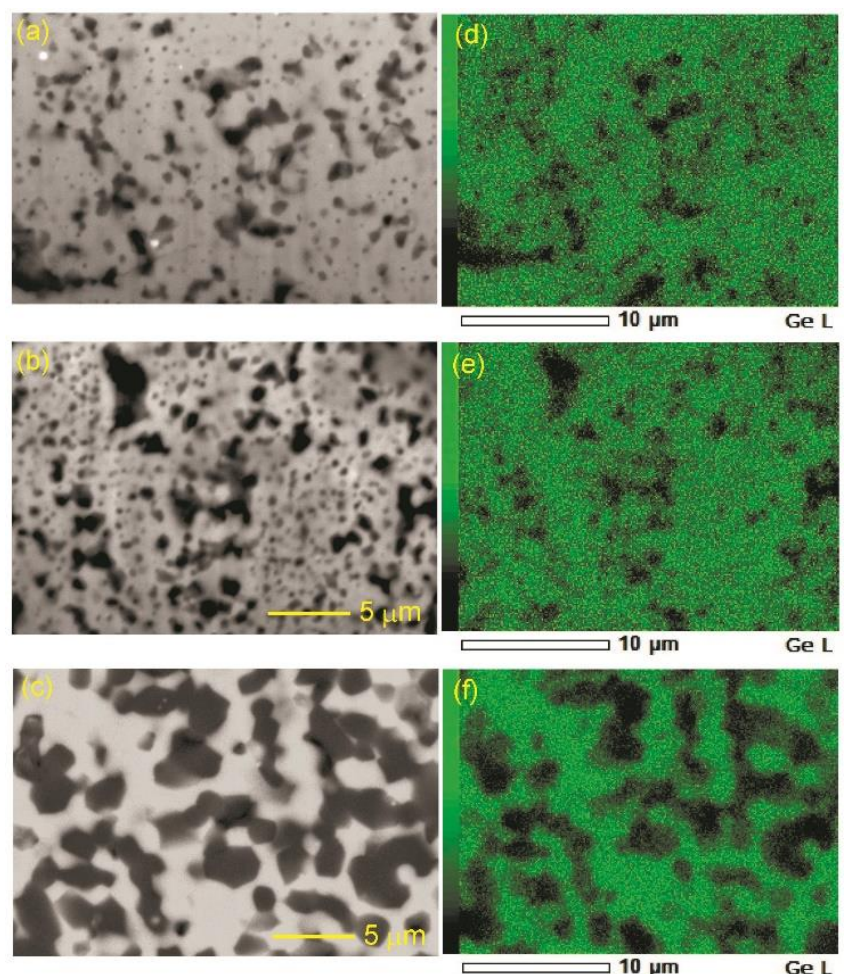

Figure S8. Cross-sectional SEM images of $(1-x) \mathrm{LGPO}-x \mathrm{Li}_{3} \mathrm{BO}_{3}$ amorphous compacts $[(\mathrm{a}) x=0.2$, (b) $x=0.33$, and (c) $x=0.5]$ after $700-^{\circ} \mathrm{C}$ heat treatment. SEM-EDX mappings of Ge $[(\mathrm{d}) x=0.2$, (e) $x$ $=0.33$, and (f) $x=0.5]$.

Table S4. Ionic conductivities of $0.5 \mathrm{LGPO}-0.5 \mathrm{Li}_{3} \mathrm{BO}_{3}$ amorphous compacts operated at $25^{\circ} \mathrm{C}$ before and after heat treatment under various conditions.

\begin{tabular}{lc}
\hline \multicolumn{1}{c}{$0.5 \mathrm{LGPO}-0.5 \mathrm{Li}_{3} \mathrm{BO}_{3}$ amorphous electrolyte } & $\begin{array}{c}\text { Conductivities } \\
\text { at } 25^{\circ} \mathrm{C} / \mathrm{S} \mathrm{cm}^{-1}\end{array}$ \\
\hline Only pressing at $800 \mathrm{MPa}$ & $1.5 \times 10^{-6}$ \\
Heating uniaxial compact at $700^{\circ} \mathrm{C}$ for $2 \mathrm{~h}$ in a conventional furnace & $1.1 \times 10^{-5}$ \\
Heating at $300^{\circ} \mathrm{C}$ for 1 min with a pressure of $400 \mathrm{MPa}$ by SPS & $5.0 \times 10^{-6}$ \\
Heating at $400^{\circ} \mathrm{C}$ for 1 min with a pressure of $400 \mathrm{MPa}$ by SPS & $6.3 \times 10^{-6}$ \\
Heating at $500^{\circ} \mathrm{C}$ for 1 min with a pressure of $400 \mathrm{MPa}$ by SPS & $9.5 \times 10^{-7}$ \\
\hline
\end{tabular}


Table S5. Reflection planes of amorphous $0.5 \mathrm{LGPO}-0.5 \mathrm{Li}_{3} \mathrm{BO}_{3}$ after SPS heat treatment at $400{ }^{\circ} \mathrm{C}$ corresponding to selected diffraction spots in Figure 5(d).

\begin{tabular}{ccc}
\hline Spot number & $d^{*} / \mathrm{nm}^{-1}$ & $\begin{array}{c}\text { Reflection plane candidate of } \\
\mathrm{Li}_{3.75} \mathrm{Ge}_{0.75} \mathrm{P}_{0.25} \mathrm{O}_{4}\end{array}$ \\
\hline ring-a & 2.55 & 210 or 011 \\
ring-b & 3.71 & 220,400 or 311 \\
ring-c & 6.42 & 620 or 040 \\
$\# 1$ & 3.91 & 200 \\
$\# 2$ & 3.96 & 200 \\
$\# 3$ & 3.96 & 200 \\
$\# 4$ & 5.31 & 402 or 222 \\
$\# 5$ & 5.37 & 402 or 222 \\
\hline
\end{tabular}
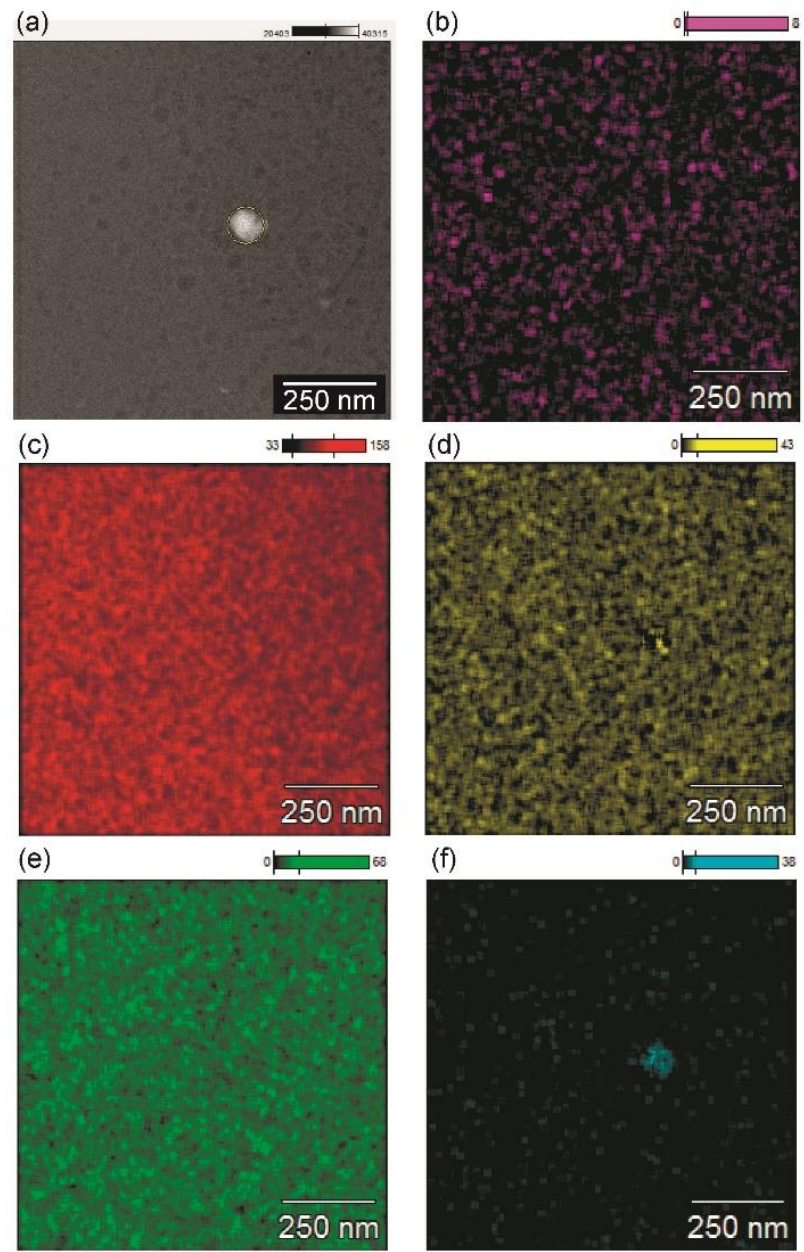

Figure S9. STEM-EDS results of $400-{ }^{\circ} \mathrm{C}-\mathrm{SPS}$ 0.5LGPO- $0.5 \mathrm{Li}_{3} \mathrm{BO}_{3}$ compact; (a) STEM image and STEM-EDS mappings of (b) B, (c) O, (d) P, (e) Ge, and (f) Zr. 


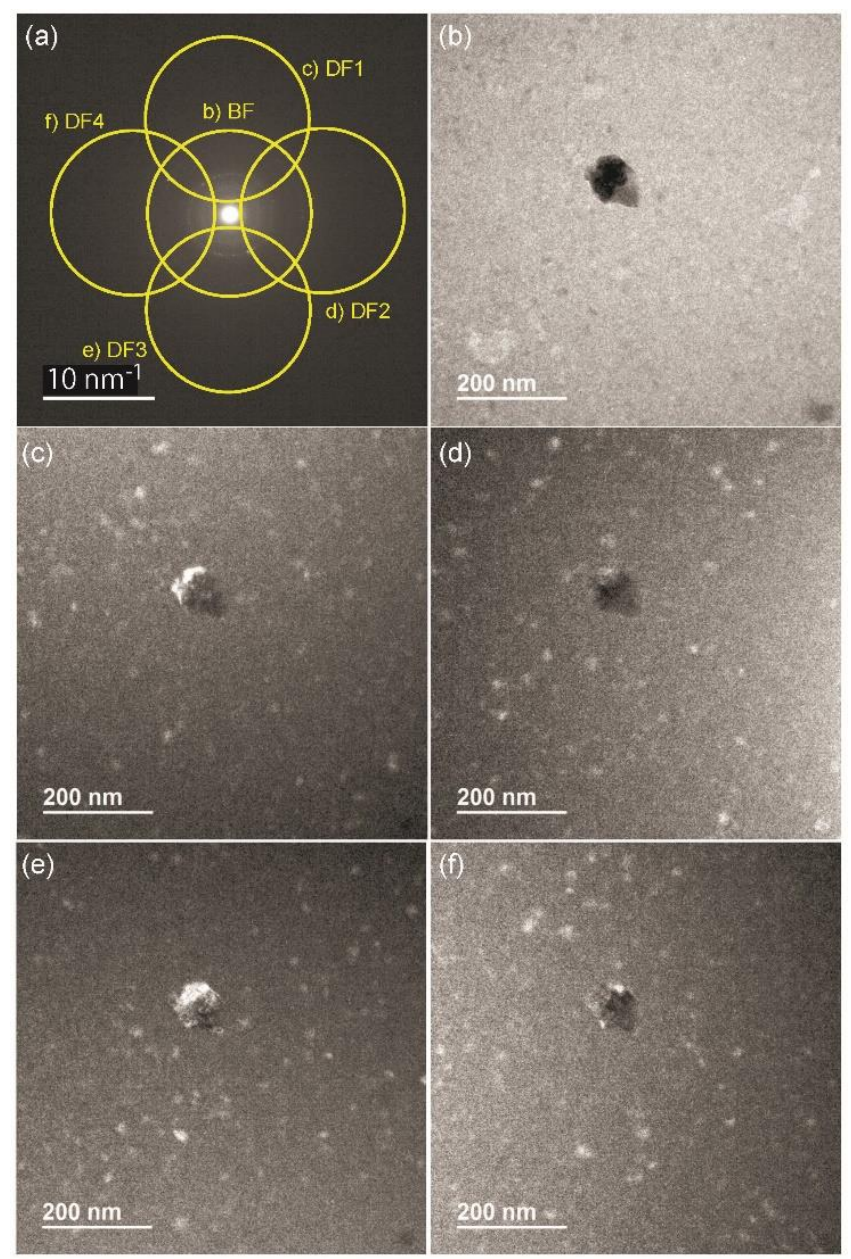

Figure S10. (a) Objective aperture locations for bright-field and dark-field TEM (yellow circles) in electron diffraction of 400 - ${ }^{\circ} \mathrm{C}$-SPS $0.5 \mathrm{LGPO}-0.5 \mathrm{Li}_{3} \mathrm{BO}_{3}$ compact. (b) Bright-field TEM image taken with the aperture indicated as circle in (a). (c-f) Dark-field TEM images taken with the aperture location shown in (a). The large grain is $\mathrm{ZrO}_{2}$ contamination. 